\title{
PELAYANAN SOSIAL LANJUT USIA KOTA BANJARMASIN
}

\author{
Muhammad Sudarsono \\ Program Studi Arsitektur Fakultas Teknik Universitas Lambung Mangkurat \\ Muhammadsudarsono10@gmail.com
}

\author{
Bani Noor Muchmad \\ Program Studi Arsitektur Fakultas Teknik Universitas Lambung Mangkurat \\ bani.nm@ulm.ac.id
}

\begin{abstract}
ABSTRAK
Pelayanan Sosial Lanjut Usia merupakan sebuah lembaga pelayanan masyarakat yang berada dibawah naungan Dinas Sosial yang ditujukan untuk meningkatkan kesejahteraan lansia dalam masa tuanya. Kurangnya lembaga ini di Kota Banjarmasin berimbas pada rendahnya angka kesejahteraan lansia di kota Banjarmasin. Perancangan Pelayanan Sosial Lanjut Usia di Kota Banjarmasin ini diharapkan dapat meningkatkan kesejahteraan lansia di kota Banjarmasin, sehingga dapat membantu mencapai tujuan dalam meningkatkan kesejahteraan lansia. Permasalahan yang diangkat pada Pelayanan sosial lansia yaitu rancangan yang mengharuskan dapat menjadi rumah yang nyaman serta menimbulkan kesan kekeluargaan pada penghuninya. Penelitian dengan menggunakan metode arsitektur perilaku sebagai acuan dalam merancang, sehingga menghasilkan konsep Homey di bangunan untuk membuat lansia tetap merasa nyaman dan menemukan arti kata sebuah rumah kembali, dalam bangunan yang berkonsepkan homey para lansia akan diarahkan untuk saling mengenal dan membuat kesan kekeluargaan diantara mereka.
\end{abstract}

Kata kunci: panti jompo, pelayanan sosial, lansia, terlantar, homey

\begin{abstract}
The Elderly Social Services is a community service institution under the auspices of the Social Service which is intended to improve the welfare of the elderly in their old age. The lack of this institution in the city of Banjarmasin has an impact on the low welfare of the elderly in the city of Banjarmasin. Designing Elderly Social Services in the city of Banjarmasin is expected to improve the welfare of the elderly in the city of Banjarmasin, to help achieve the goal of improving welfare of the elderly. The problem raised in the elderly social services is the design that requires it to be a comfortable home and gives the impression of kinship to its inhabitants. Research using behavioral architectural methods as a reference in designing, so as to produce a Homey concept in buildings to make the elderly feel comfortable and find the meaning of the word back home, in buildings that conceptualize the homey of the elderly will be directed to know each other and make a family impression between them.
\end{abstract}

Keywords: nursing home, social services, elderly, neglected, comfortable

\section{PENDAHULUAN}

Lansia dapat diartikan dengan suatu kondisi dimana seseorang sudah tidak bisa mempertahankan keadaan dirinya dengan kesehatan mental yang ada. Hal ini berkaitan erat dengan tingkat kepekaan serta daya ingat yang dimiliki seseorang (Efendi, 2009). UU No 13 Tahun 1998 pasal 1 mengartikan lansia adalah Pribadi yang telah mencapai umur lebih dari 60 tahun.
Ada juga lansia potensial yang diartikan lansia yang masih produktif atau masih bisa menghasilkan sesuatu.

Lansia dibedakan menjadi dua jenis. 1) Terlantar secara ekonomi yang diartikan, suatu keadaan seseorang terhambat karena memerlukan konsumsi dan mengharuskan produksi. 2) Terlantar Secara sosial dimana seseorang mengalami kesepian disebabkan ditinggalkan keluarga terdekatnya. Di Kota Banjarmasin sendiri memiliki \pm 700869 Ribu 
jiwa dan diantaranya ada sekitar $\pm 46,896$ (BPS Kalsel) untuk yang berusia lanjut, dari $\pm 46,896$ jiwa ada $\pm 17,179$ jiwa yang berada dibawah angka kemiskinan dan beberapa diantaranya tinggal sendirian. Untuk kecamatan Banjarmasin utara ada sekitar \pm 3334 jiwa, Banjarmasin timur \pm 2807 jiwa, Banjarmasin Selatan \pm 4693 jiwa, Banjarmasin barat \pm 3680 jiwa dan pada Banjarmasin tengah ada sekitar \pm 2665 jiwa (DINAS SOSIAL PEMKO BANJARMASIN). Pada Panti Werdha Budi Sejahtera Provinsi Kalimantan selatan ada 174 orang yang dirawat disana dan 62 orangnya berasal dari Banjarmasin (Data PSTW Provinsi Kalsel). Pelayanan masyarakat untuk lanjut usia di Banjarmasin hanya ada beberapa buah dan diantaranya ada yang berbentuk rumah tinggal biasa dan berukuran kecil, selain itu pusat pelayanan untuk lansia seperti klinik lansia di kota Banjarmasin juga terbilang sangat minim.

Pembangunan Pusat pelayanan Sosial Lanjut usia dengan fasilitas-fasilitas yang mempunyai seperti rumah tinggal, ruang kesehatan, ruang therapy, ruang hydrotherapy serta fasilitas yang hanya sekedar sebagai penyalur hobi lansia di kota Banjarmasin sangat diperlukan dan hal ini ditujukan untuk mendukung program pemerintah dalam meningkatkan jumlah harapan hidup, produktivitas, dan kesejahteraan pada lansia.

\section{PERMASALAHAN}

Bagaimana rancangan pelayanan sosial lanjut usia yang dapat menjadi rumah yang nyaman serta menimbulkan kesan kekeluargaan pada penghuninya.

\section{TINJAUAN PUSTAKA}

\section{A. Tinjauan Arsitektural}

Menurut WHO, lansia ialah Pribadi yang sudah memasuki usia diatas 60 tahun dan sudah memasuki batasan akhir fase kehidupan. Ketika menjadi lansia akan terjadi suatu keadaan dimana tubuh mulai kehilangan fungsi ditandai dengan semakin rentannya tubuh, sering diserang penyakit, dan mengalami keriput atau penuaan. Hal tersebut dapat menyebabkan kematian.
Pelayanan sosial dapat diartikan sebagai aktivitas seseorang yang dapat memperbaiki lingkungan sekitar (Wibhawa dkk, $2010: 24$ )

\section{B. Tinjauan Konsep}

Homey dalam kata lainnya adalah suasana rumah yang terasa nyaman bagi para penggunanya. Maksud Rumah disini adalah suatu tempat yang tidak hanya bangunan nyata, melainkan tempat yang memenuhi syarat kehidupan yang layak, dipandang layak secara pribadi maupun pandangan masyarakat sekitar. Rumah juga dapat dimaknai sebagai tempat ternyaman untuk menikmati kehidupan dan peristirahatan.

\section{METODE}

Metode yang digunakan untuk menciptakan persepsi konsep homey adalah metode arsitektur perilaku. Metode Arsitektur Perilaku dianggap paling tepat dikarenakan dalam menciptakan kesan yang nyaman bagi para lansia mengaitkan antara perilaku dan penggunaan bangunan yang dirancang. Pendekatan yang dilakukan ialah arsitektur perilaku dengan memfokuskan kepada perancangan ruang untuk lansia dengan menyesuaikan standar dan keamanan untuk menggapai kebutuhan dan aktivitas dari sudut pandang arsitektural, serta mewujudkan pelayanan aktivitas setiap waktu para lansia. Bangunan yang diciptakan untuk memenuhi segi arsitektural, melalui pendekatan arsitektur perilaku yang menghasilkan suatu lingkungan dengan perencanaan pusat pelayanan sosial yang menunjang dengan memfasilitasi semua aktivitas lansia agar menciptakan kesan homey.

\section{PEMBAHASAN}

\section{A. Lokasi}

Tapak terletak pada Jalan Beruntung Jaya di Kota Banjarmasin yang memiliki luas wilayah 98,46 km² (98,45 ha).. Banjarmasin terbagi atas 5 kecamatan dan 52 kelurahan

Letak geografis Kota Banjarmasin adalah $114^{\circ} 32^{\prime} \mathrm{BT}$ dan $3^{\circ} 15^{\prime}-3^{\circ} 22^{\prime}$ LS batas-batas administratif sebagai berikut:

- Dari Selatan : Banjar (Kab) 
- Dari Utara

: Barito Kuala (Kab)

- Dari Timur

: Banjar (Kab)

: Barito Kuala (Kab)

- Tapak terletak di Jalan Beruntung Jaya

- Luas Lahan: $31.500 \mathrm{~m}^{2}$.

○

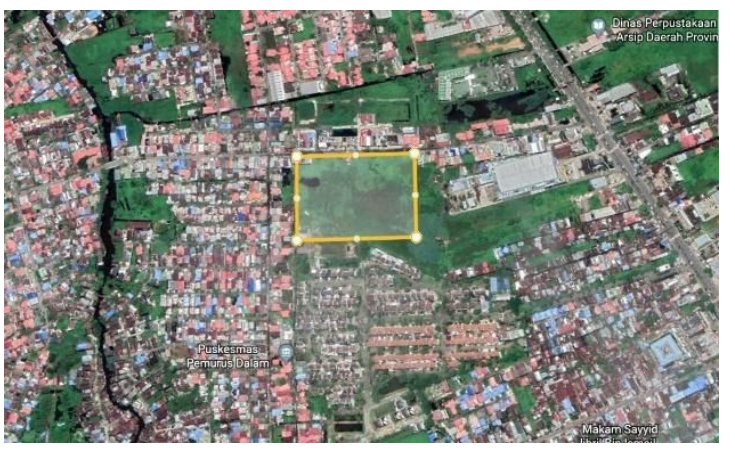

Gambar 19 Lokasi Tapak

Sumber Google Maps

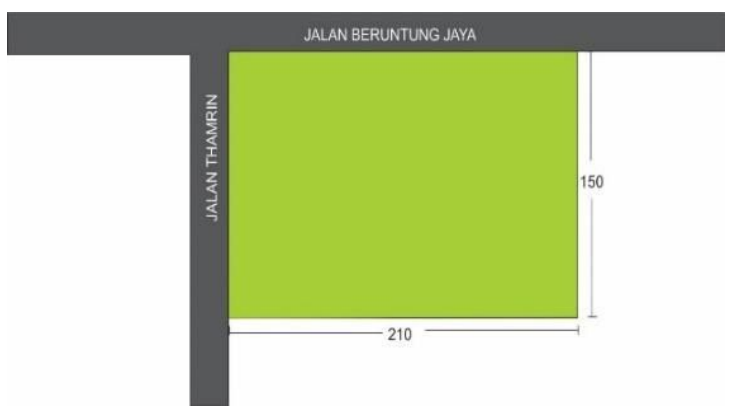

Gambar 2 Luasan Tapak

Dasar pertimbangan dalam memilih lokasi adalah sebagai berikut:

- Terjangkau sarana dan prasarana perkotaan, jaringan utilitas dan pencapaian.

- Sesuai dengan ketentuan pemerintah tentang fungsi atau tata guna lahan.

- Belum adanya Pelayanan Sosial Lanjut Usia

- Keadaan alam yang masih dipenuhi pohon yang bagus

- Dari pertimbangan kriteria di atas maka lokasi yang dipilih untuk perancangan Pusat Pelayanan Sosial Banjarmasin adalah Jl. Beruntung Jaya Kota Banjarmasin, Kalimantan Selatan 70248 Dalam pemilihan lokasi tapak juga

- mempertimbangkan berbagai aspek sebagai berikut:

\section{Kelebihan Tapak}

- Kemudahan pencapaian baik bagi pengendara bermotor maupun bagi pejalan kaki.
- Lokasi strategis berada di dekat jalan utama.

- Fasilitas dan utilitas yang tersedia mencukupi.

- Akses menuju rumah sakit Provinsi Kalimantan selatan mudah.

- Penghawaan dan keadaan alam di tapak masih asri dan hal ini membuat tapak sesuai dengan kondisi yang diinginkan.

\section{Kekurangan Tapak}

- Tapak berada di jalan yang cukup besar hal ini membuat area depan sangat bising dan berdebu.

- Area selatan tapak bersinggungan dengan area perumahan.

- View belakang tapak yang kurang menarik.

3. Batasan Tapak

Dengan batasan tapak sebagai berikut:

- Utara : Jalan Beruntung Jaya

- Timur : Giant Extra

- Selatan : Perumahan Citra Garden

- Barat : jalan Thamrin

4. Peraturan Pemerintah

- KDB : $60 \%$

- GSB : 15 Meter

- KLB : $2,8 \%$

\section{B. Analisis}

\section{Analisis Matahari}

Analisis matahari berpengaruh pada penataan landscape serta penataan zoning pada bangunan. Sinar matahari pagi sangat baik bagi kesehatan, terutama pada perancangan pelayanan sosial lanjut usia. Pada analisis di atas dapat dilihat bahwa bagian barat daya yang terkena matahari sore. Oleh karena itu, pada bagian barat daya akan ditambahkan pohon peneduh. Area timur akan dijadikan zona ruang terbuka karena terkena matahari pagi.

Analisis matahari berpengaruh pada penataan landscape serta penataan zoning pada bangunan. Sinar matahari pagi sangat baik bagi kesehatan, terutama pada perancangan pelayanan sosial lanjut usia. Pada analisis di atas dapat dilihat bahwa bagian barat daya yang terkena matahari sore. Oleh karena itu, pada bagian barat daya akan ditambahkan pohon peneduh. 
Area timur akan dijadikan zona ruang terbuka karena terkena matahari pagi
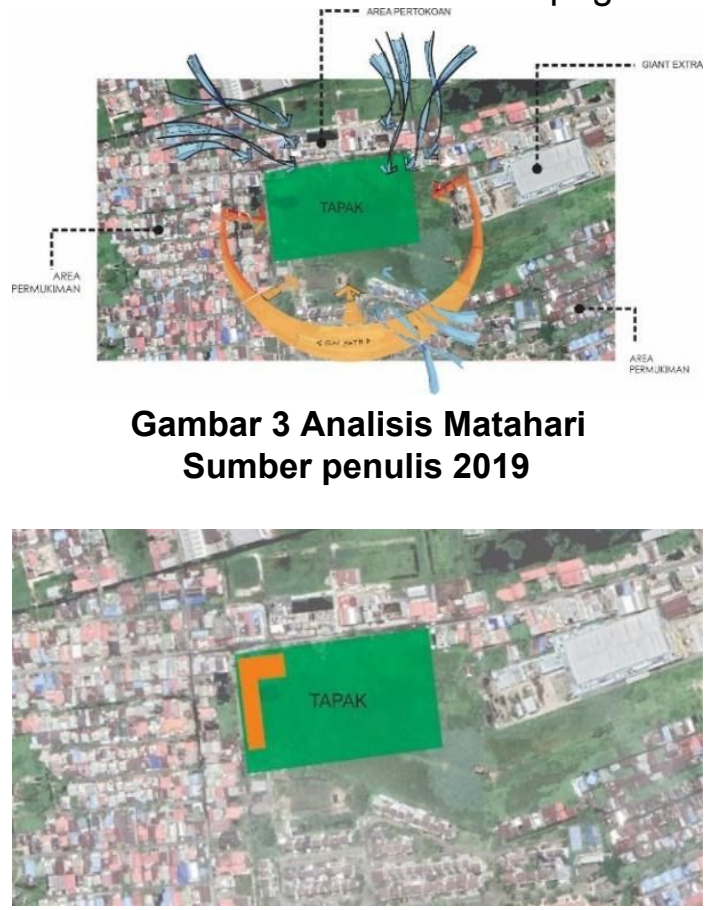

Gambar 4 Zona Panas pada tapak

Ada beberapa cara dapat dilakukan agar mereduksi panas matahari berlebih di area barat salah satunya dengan ;

- Pohon

Pohon memiliki banyak jenis dan jenis yang cocok untuk mereduksi cahaya matahari adalah pohon pohon yang memiliki diameter besar.
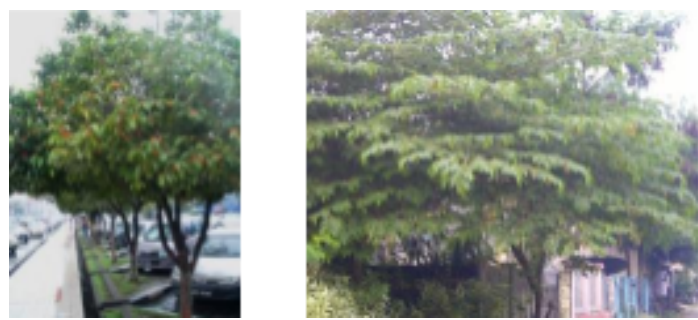

Gambar 5 Penggunaan Vegetasi

- Sun Shading

Sun Shading berfungsi untuk mereduksi sinar matahari yang masuk pada bangunan biasanya terletak pada bukaan bukaan yang tersedia pada bangunan.

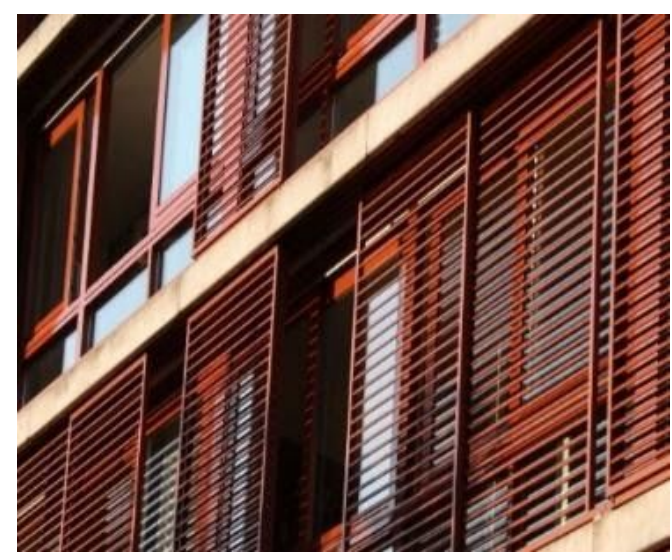

Gambar 6 Sun Shading

- Kolam

Selain menambahkan nilai keindahan dan ketenangan kolam air juga dapat mereduksi panas yang diakibatkan sinar matahari terlalu banyak.

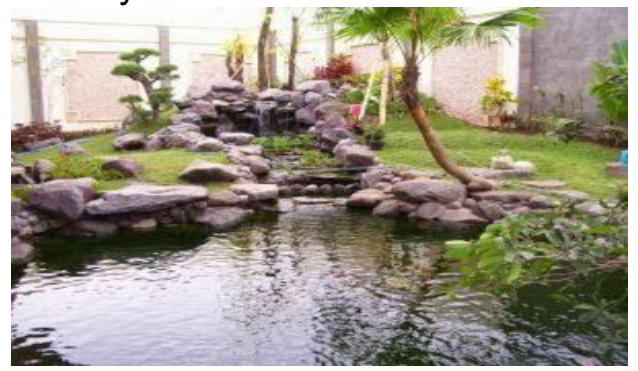

Gambar 7 Kolam

\section{Analisis Penghawaan dan Vegetasi}

Analisis Penghawaan bertujuan untuk mengetahui bagaimana kondisi udara dan penghawaan pada tapak dan ini akan digunakan untuk penggunaan bukaan seperti jendela agar dapat menjadi jawaban pada bagian bagian yang panas berlebihan.

Tapak berada didaerah yang pada area belakang memiliki banyak area terbuka hijau, area terbuka hijau ini diharapkan dapat membawa angin segar sehingga dapat terjadinya pergantian hawa-hawa panas digantikan oleh udara yang baru dari area belakang. Angin dari area belakang ini akan dibuatkan sirkulasi khusus untuk dapat mengalir dari bagian belakang ke bagian depan tapak.

Memperbanyak bukaan pada bangunan yang memerlukan intensitas angina sejuk untuk mengurangi udara yang kurang sedap pada bangunan. Pada kawasan, dibutuhkan sirlukasi yang besar pada bagian belakang dan samping tapak untuk memperoleh udara yang segar dari luar tapak. 


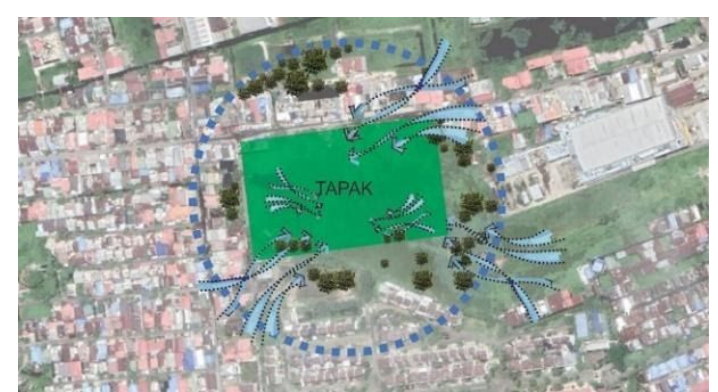

Gambar 8 Analisis Penghawaan dan Vegetasi

\section{Analisis Kebisingan dan Debu}

Analisis Kebisingan dan Debu berpengaruh pada penataan lansekap pada bagian depan kawasan, untuk mengurangi intensitas debu dan suara yang masuk pada kawasan maka penanaman pohon serta tumbuhan tumbuhan agar dapat mereduksi suara dan debu yang dihasilkan oleh jalan raya di depan tapak.

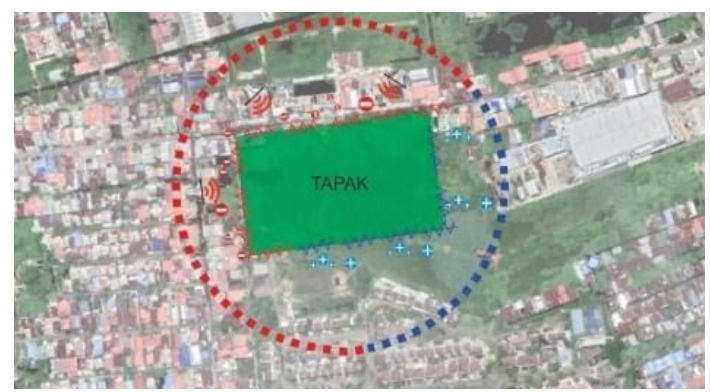

Gambar 9 Analisis Kebisingan dan Debu

\section{Analisis Pencapaian Tapak}

Tapak berada pada daerah yang lumayan padat, akses menuju tapak sangat lah mudah. Jarak tapak ke rumah sakit terdekat sekitar $1,5 \mathrm{~km}$ bisa ditempuh dalam waktu kurang lebih 10 menit perjalanan.

Di Dalam tapak telah tersedia PLN dan PDAM yang berfungsi dengan baik. Selain itu tapak dapat diakses dengan jalan kaki, seda motor, mobil dan bersepeda. Jalan di depan tapak lumayan besar berukuran lebar 10 meter.

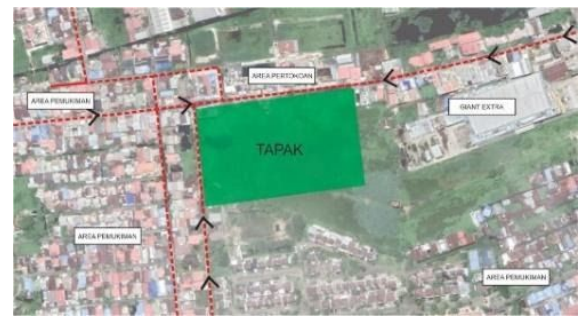

Gambar 10 Analisis Pencapaian Tapak

\section{RUANG DAN BENTUK}

Jadi, untuk mendapatkan rancangan yang homey diperlukan pembentukan struktur material, warna, ruang dengan mengedepankan estetika ruangan yang dibuat. Berdasarkan hal tersebut, diperlukan sebuah tema pada bangunan yang dapat mencapai maksud dan tujuan bangunan.

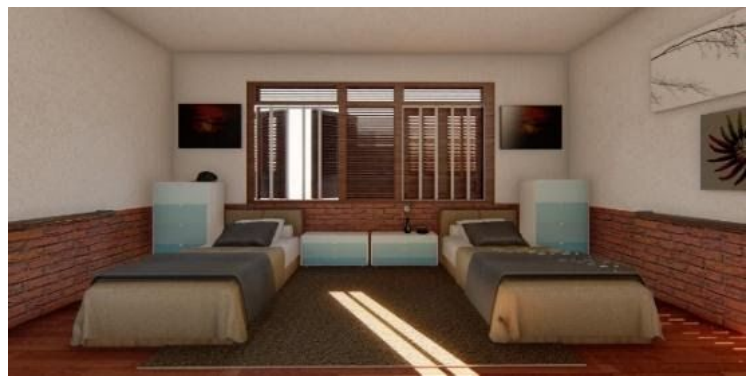

Gambar 11 Interior Kamar

Tema yang dipilih adalah rumah dengan nuansa bahari. Hal hal yang dapat diambil dari rumah era dulu di aplikasi kan pada bangunan pelayanan sosial lanjut usia yang juga ada beberapa material yang diambil dari zaman modern. Tapi kesan bangunan akan dikembalikan ke 60 tahun sebelum 2019 agar menciptakan kesan rumah para lansia ketika muda.

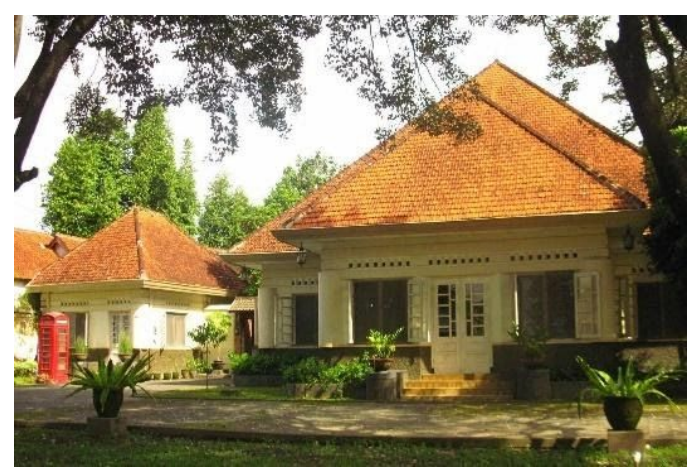

Gambar 12 Bangunan Zaman Dulu

\section{Interior}

Mengingat kondisi tubuh lansia yang sudah tidak lagi dapat dikatakan baik-baik saja maka pada ruang-ruang hunian akan diberikan vegetasi yang dapat membantu untuk meningkatkan nilai-nilai yang ada ada sebuah ruang.

Ficus:

- Menambahkan nilai keindahan untuk ruang dalam

- Dapat mengurangi bau dalam ruangan 
- $\quad$ Mudah dirawat

- Bernilai tinggi

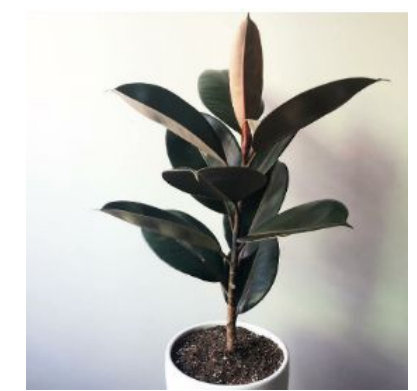

\section{Gambar 13Tanaman Ficus}

Lily:

- Menambahkan nilai keindahan untuk ruang dalam

- Dapat mengurangi radiasi yang dihasilkan oleh barang barang elektronik

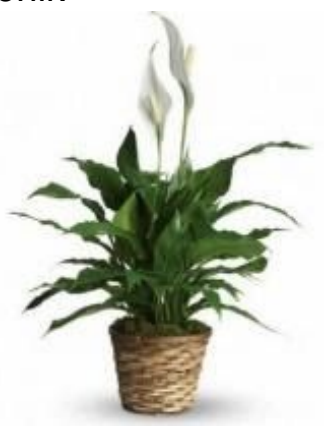

Gambar 14 Tanaman Lily

\section{Kaktus Karibi:}

- Menambahkan nilai keindahan untuk ruang dalam

- Dapat mengurangi radiasi yang dihasilkan oleh barang barang elektronik

- Mudah dirawat

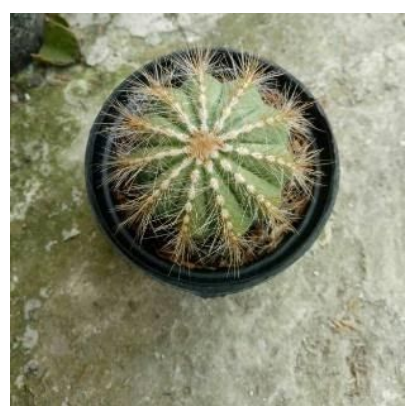

Gambar 15 Tanaman Kaktus Karibi

Lidah Mertua:
- Menambahkan nilai keindahan untuk ruang dalam

- Bentuknya yang tergolong kecil dapat dilakukan disemua tempat

- Dapat menyerap bahan pencemar (Polutan) yang berbahaya seperti pada racun asap rokok dan Formaldehida $\left(\mathrm{CH}_{2} \mathrm{O}\right)$

- Mudah dirawat

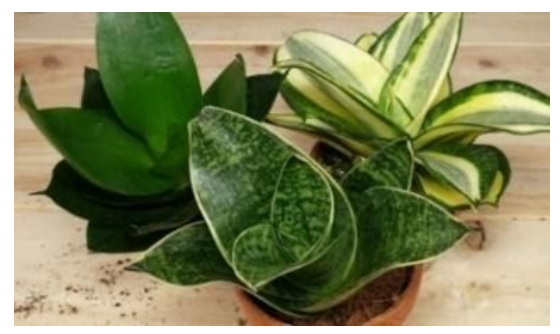

Gambar 16 Tanaman Lidah Mertua

\section{Pakis Boston :}

- Menambahkan nilai keindahan untuk ruang dalam

- Stomata terdapat pada tanaman ini berfungsi sebagai penyerap asap rokok yang beracun (CO) dan mengeluarkan $\left(\mathrm{O}_{2}\right)$ Sebagai udara yang bersih.

- Banyak dari peneliti menyarankan untuk meletakkan tumbuhan ini diruang ruang besar.

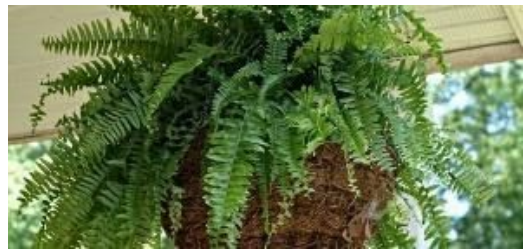

Gambar 17 Tanaman Lidah Mertua

\section{KONSEP RANCANGAN}

\section{Konsep Program}

Tujuan utama adalah meningkatkan kesejahteraan lansia kota Banjarmasin dengan memunculkan kesan yang nyaman bagi pengguna. Maka dari itu diterapkan konsep "homey" melalui suasana yang akan diterapkan pada tiap tiap bangunan dengan menyetting elemen-elemen arsitektur dengan tema bangunan 60 tahun sebelum tahun 2019, sehingga para pengguna dapat merasakan kenangan-kenangan mereka ketika muda dan

perasaan-perasaan ketika mereka masih dapat melakukan banyak aktivitas, 
dan hal ini ditujukan akan membuat para lansia bersemangat untuk tetap menjalankan kehidupan dengan produktif hingga saling mengenal satu sama lain dan menimbulkan kesan kekeluargaan dari satu sama lain

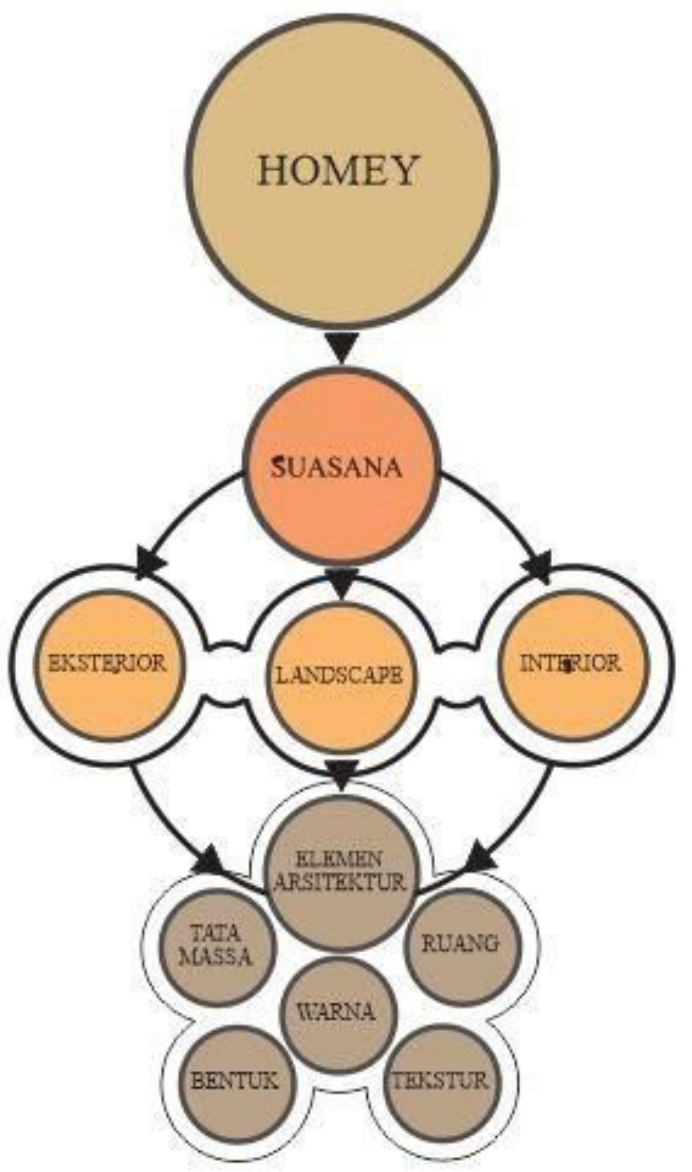

Gambar 20 Konsep Sumber Penulis 2019

\section{Konsep Rancangan}

Konsep perancangan merupakan gagasan yang diperoleh dari proses analisis maupun tinjauan pustaka yang telah dibahas sebelumnya. Konsep perancangan yang dibahas meliputi konsep bentuk bangunan, konsep fasade bangunan, konsep susunan ruang, konsep sirkulasi, konsep penyajian informasi dan konsep interior ruang pamer.

Tema yang digunakan dalam rancangan Pelayanan Sosial Lanjut Usia Banjarmasin adalah Homey. Tema homey diangkat berdasarkan permasalahan yang ada pada keresahan lansia terlantar. Dalam bahasa Indonesia mempunyai arti "tempat yang maknanya nyaman $\mathrm{Hal}$ yang ingin dicapai dalam penerapan tema diatas adalah agar para lansia dapat menikmati huniannya sebagai tempat yang nyaman dan dapat mewadahi aktivitasnya serta menimbulkan kesan kekeluargaan pada penghuninya, Konsep ini diterapkan pada desain ruang dalam dan ruang luar.. Selain itu bentukan dari hunian lansia juga di setting seperti rumah di masa lalu, hal ini terlihat dari bentuk ,tekstur serta material diterapkan pada bangunan.

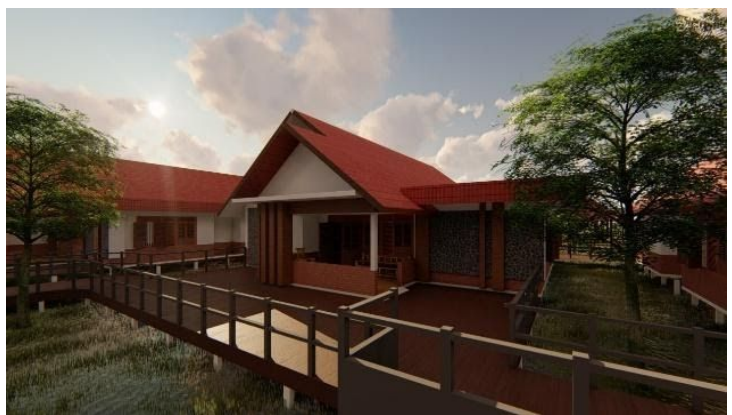

Gambar 21 Perspektif Bangunan Sumber Penulis 2019

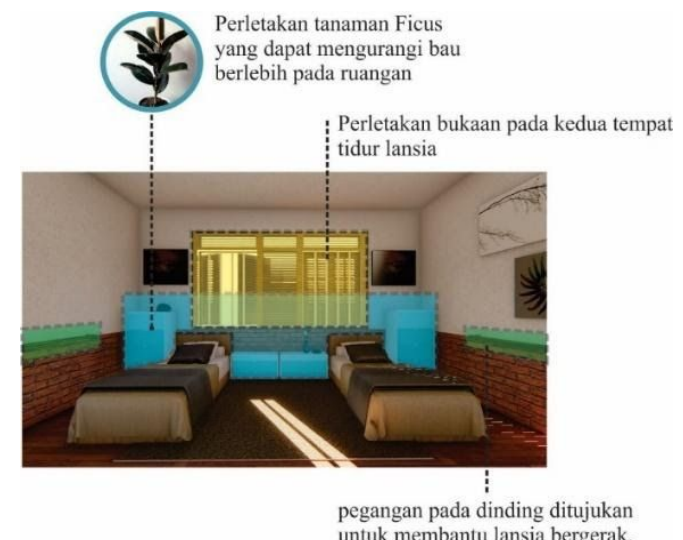

Gambar 20 Penerapan Interior Kamar Sumber Penulis 2019

\section{Konsep Interior}

Konsep yang akan diterapkan pada ruang interior hunian lansia fokus pada kenyamanan sirkulasi dan perletakan perabot yang dapat mempermudah aktivitas para lansia. Penataan perabot pada kamar tidur lansia diletakkan untuk memudahkan pergerakan lansia,selain itu di ruang ruang alam diberikan tanaman yang memiliki fungsi untuk mengurangi bau pada ruangan, mengurangi racun diudara pada hunian lansia, selain itu ada juga tanaman yang berfungsi untuk mengurangi jumlah polusi dan asap yang diakibatkan oleh pembakaran atau asap bekas memasak di dapur. 


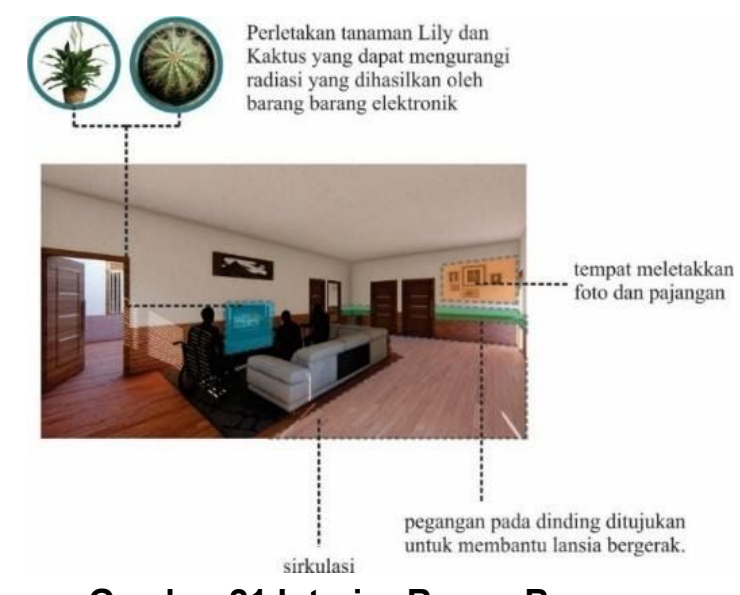

Gambar 21 Interior Ruang Bersama

Pada area ruang bersama dibuat untuk dapat menampung banyak lansia dan berbagai aktivitas seperti berkumpul atau keterampilan bagi lansia yang sudah tidak dapat berjalan jauh ke bangunan khusus keterampilan. Karena area bersama media elektronik seperti tv juga elektronik lainnya yang memiliki radiasi maka pada ruang ini akan diberikan tanaman yang dapat mengurangi radiasi yang dihasilkan oleh elektronik.

\section{Konsep Lansekap}

Diantara hunian lansia diberikan pot tanaman vertikal untuk meletakkan pot pot tumbuhan, hal ini ditujukan untuk memfasilitasi para lansia yang gemar bercocok tanam selain itu hal ini menambahkan nilai pemandangan dari dalam hunian ke arah luar. Tanaman ini juga memberikan rasa sejuk dan rasa indah dari tiap tiap tanaman yang diletakkan.

Akses dari antar bangunan akan melewati jalan yang bermaterial papan kayu, hal ini diambil dari kebiasaan rumah - rumah yang ada di kota Banjarmasin yang dihubungkan melalui titian. Hal ini juga ditujukan untuk memberi kesan homey pada pengguna ketika melalui jalan ini.

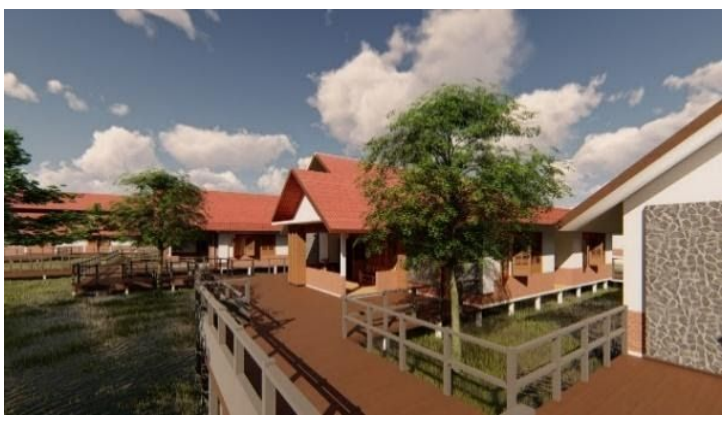

\section{Gambar 22 Perspektif Hunian lansia}

\section{KESIMPULAN}

Pelayanan sosial lansia kota
Banjarmasin adalah solusi untuk meningkatkan kesejahteraan lansia terlantar kota Banjarmasin. Pelayanan Sosial lanjut usia yang baik dapat mewadahi segala macam aktivitas dan kebiasaan lansia kota Banjarmasin lewat fasilitas-fasilitas yang tersedia dengan sangat memikirkan nilai-nilai kenyamanan, kemudahan, dan keamanan.

Permasalahan arsitektur yang diangkat bagaimana rancangan pelayanan sosial lanjut usia yang dapat menjadi rumah yang nyaman serta menimbulkan kesan kekeluargaan pada penghuninya. Metode yang dipilih untuk mengantarkan pada tujuan yang diinginkan adalah Metode Arsitektur Perilaku dimana metode ini dipakai dalam menentukan setiap aspek yang ingin dituju dengan pertimbangan keseharian dan aktivitas para pengguna khususnya lansia.

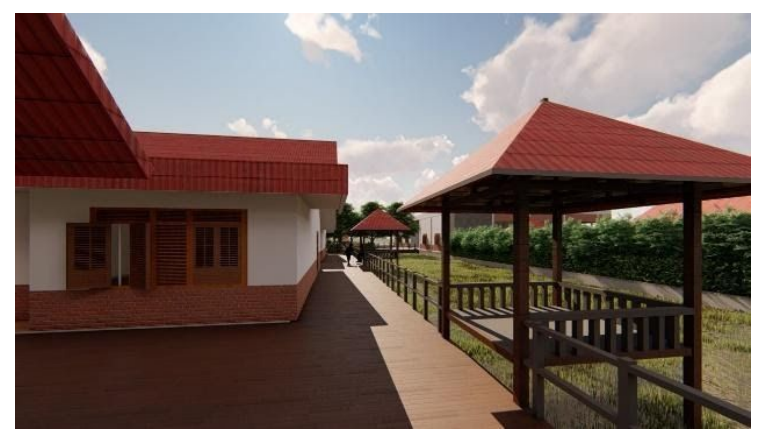

Gambar 23 Perspektif Belakang hunian Lansia

Melalui metode ini menghasilkan konsep homey yang akan mengantarkan para pengguna pada kesan rumah. Konsep diaplikasikan pada interior, eksterior dan lanskap yang didesain, konsep ini juga mengantarkan perasaan kekeluargaan pada para penghuninya. Dengan perancangan ini diharapkan dapat meningkatkan para lansia terlantar ini pada kesejahteraan dan kehidupan yang layak di masa tuanya.

\section{DAFTAR PUSTAKA}

Ahrishar, M. 2016. Profil Kota Banjarmasin. http://muhammadahrishar.blogspot.co m/2016/03/profil-kota-banjarmasin. html 
Badan Pusat Statistik Republik Indonesia. https://www.bps.go.id/

Badan Pusat Statistik Kota Banjarmasin. https://banjarmasinkota.bps.go.id/

Desi. (2003). Fungsi Ruang dalam Arsitektur.

jiunkpe/s1/desi/2003/jiunkpe-ns-s1-200 3-41498093-457- interiorchapter3. pdf.

Fitriani, D. dan Arief Hidayat. (2018). Elemen Interior Terhadap Keamanan Sirkulasi Lansia. Jurnal Lingkungan Binaan Indonesia, 7(3), 124-134.

Komisi Nasional Lanjut Usia. (2010). Profil Penduduk Lanjut Usia 2009. Jakarta: Komnas Nasional Lanjut Usia.

Soetarso. (1980). Kesejahteraan Sosial, Pelayanan Sosial dan Kebijaksanaan Sosial. Bandung: Sekolah Tinggi Kesejahteraan Sosial (STKS). 